\title{
WILLIAM POOLE
}

Brown University

\section{Interpreting the Fed's Monetary Targets}

House CONCURRENT Resolution 133, passed in March 1975, requires that

... the Board of Governors shall consult with Congress at semi-annual hearings before the Committee on Banking, Housing and Urban Affairs of the Senate and the Committee on Banking, Currency and Housing of the House of Representatives about the Board of Governors' and the Federal Open Market Committee's objectives and plans with respect to the ranges of growth or diminution of monetary and credit aggregates in the upcoming twelve months ...

The Federal Reserve has responded by setting targets for four different variables: $\mathrm{M}_{1}, \mathrm{M}_{2}, \mathrm{M}_{3}$, and the bank-credit proxy. ${ }^{2}$ (The proxy was later dropped from the list.) The first set of one-year targets covered the period from March 1975 to March 1976, while the second, third, and fourth sets were defined in terms of the growth of the quarterly average of the targeted variables from the second, third, and fourth quarters of 1975 to the corresponding quarters of 1976. The purpose of this report is to analyze initial experience with this targeting procedure.

The first and second sections outline the features and problems of the present targeting procedures, and the third examines the operational significance of the announced targets. An alternative method of expressing monetary targets is suggested next, and the final section offers a few comments on the possibility, suggested by some, of adding interest-rate targets to the present system.

1. Conduct of Monetary Policy, Conference Report to Accompany H. Con. Res. 133, Rept. 94-91, 94:1 (Government Printing Office, 1975), p. 1.

2. For definitions of these monetary aggregates, see table 1 , note $c$. 


\section{Table 1. Growth Targets of Money and Credit Measures, and Actual Growth, Various Periods, March 1975-Fourth Quarter 1976}

Percent change at annual rates

\begin{tabular}{|c|c|c|c|c|}
\hline \multirow[b]{2}{*}{ Interval ${ }^{\mathbf{a}}$ and type of growth ${ }^{\mathbf{b}}$} & \multicolumn{4}{|c|}{ Monetary measure ${ }^{\circ}$} \\
\hline & $M_{1}$ & $M_{2}$ & $M_{3}$ & Credit proxy \\
\hline \multicolumn{5}{|l|}{ March 1975-March 1976} \\
\hline Target & $5-7.5$ & $8.5-10.5$ & $10-12$ & $6.5-9.5$ \\
\hline Actual & 5.0 & 9.4 & 12.1 & 3.3 \\
\hline \multicolumn{5}{|l|}{$1975: 2-1976: 2$} \\
\hline Target & $5-7.5$ & $8.5-10.5$ & $10-12$ & $6.5-9.5$ \\
\hline Actual $^{d}$ & 4.4 & 9.0 & 11.6 & 3.2 \\
\hline \multicolumn{5}{|l|}{$1975: 3-1976: 3$} \\
\hline Target & $5-7.5$ & $7.5-10.5$ & $9-12$ & e \\
\hline Actual $^{\mathrm{d}}$ & 3.2 & 8.3 & 10.6 & $\ldots$ \\
\hline \multicolumn{5}{|l|}{$1975: 4-1976: 4$} \\
\hline Target & $4.5-7.5$ & $7.5-10.5$ & $9-12$ & $\theta$ \\
\hline Actuald $^{d}$ & 3.8 & 9.8 & 11.3 & $\ldots$ \\
\hline
\end{tabular}

Sources: Targets, Federai Reserve Bulletin, vol. 61 (May 1975), p. 286; (August 1975), p. 495; (November 1975), p. 747, and vol. 62 (February 1976), p. 124. Actual, ibid. (April 1976), p. 12, and Board of Governors of the Federal Reserve System, Statistical Release H.6, May 6, 1976.

a. On May 1, 1975, the targets for March 1975 to March 1976 were announced; on July 24, 1975, for 1975:2 to 1976:2; on November 4, 1975, for 1975:3 to 1976:3; and on February 3, 1976, for 1975:4 to 1976: 4 .

b. The actual growth rates are calculated from seasonally adjusted data.

c. $\mathbf{M}_{1}$ consists of demand deposits at commercial banks plus currency in circulation; $\mathbf{M}_{2}$ is $\mathbf{M}_{1}$ plus savings and time deposits at commercial banks other than large-denomination negotiable certificates of deposit; $\mathbf{M}_{\mathbf{3}}$ is $\mathbf{M}_{2}$ plus deposits at mutual savings banks, savings and loan shares, and credit union shares; the credit proxy is total member-bank deposits subject to reserve requirements, plus Eurodollar borrowings, loans sold to bank-related institutions, and certain other nondeposit items.

d. Actual growth rate from base quarter to March 1976, the latest information available at time of this writing.

e. Not targeted.

In the discussion below, I have attempted to avoid all issues of the desirability of House Concurrent Resolution 133, as well as general issues of Federal Reserve independence. The relative merits of various monetary aggregates as policy targets will not be examined-the use of $M_{1}$ rather than $M_{2}$ or $M_{3}$ in the figures reflects expositional convenience only-and finally, except for a few comments in the last section, the advisability of monetary targets rather than interest-rate targets will not be discussed.

I do discuss issues concerning the comprehensibility of announced targets to the Congress and the general public. Whatever the political merits of House Concurrent Resolution 133, the mechanism should not be vulnerable to confusion caused by correctable defects in the way monetary targets are expressed and explained by the Federal Reserve. 


\section{Present Monetary-Targeting Procedures}

Table 1 summarizes the targets and experience to date with the quarterly procedure initiated in 1975. According to the preliminary data available for March 1976, the $M_{1}$ and $M_{2}$ targets for March 1976 were met, $M_{3}$ ran a whisker above its target range, and the credit proxy fell well below its range. The second, third, and fourth target announcements pertain to dates still in the future at the time of this writing; hence, for each of these periods, the entries in the table present the actual growth rates from the base quarters to March 1976, and may be viewed as "progress reports."

An examination of the table raises a question: Why was the first target range of $M_{1}$ met and yet, according to the progress reports, $M_{1}$ growth subsequently fell below the target ranges?

Figure 1 provides the answer to this question. In the figure each vertical bar shows the target range in the level of $M_{1}$, calculated by applying the target growth range to the base level shown at the apex of each conelike figure, which in turn is formed by connecting the ends of the bars to the base level. ${ }^{3}$ Only the vertical bars themselves should be considered the targets, but a comparison of actual $\mathrm{M}_{1}$ to the cones visualizes the progress reports. Since the money stock has not remained on the axes of the cones defined by earlier announcements, the base level underlying each new announcement-and therefore the target range for one year ahead in terms of the level of $\mathrm{M}_{1}$-has to some extent been inconsistent with previously announced targets.

The Fed has defined targets for other aggregates in the same way as for $M_{1}$, and therefore the problem illustrated by figure 1 is not confined to that aggregate. To date the inconsistencies have been smaller for $\mathrm{M}_{2}$ and $M_{3}$ than for $M_{1}$, but they need not remain so in the future.

\section{Problems with the Current Procedures}

The current targeting procedure has two defects, one major and the other minor. The major one is the probability of generating successive

3. Since the second, third, and fourth announcements defined targets in terms of quarterly averages, the vertical bars have been placed at the middle months of the quarters for these targets. 


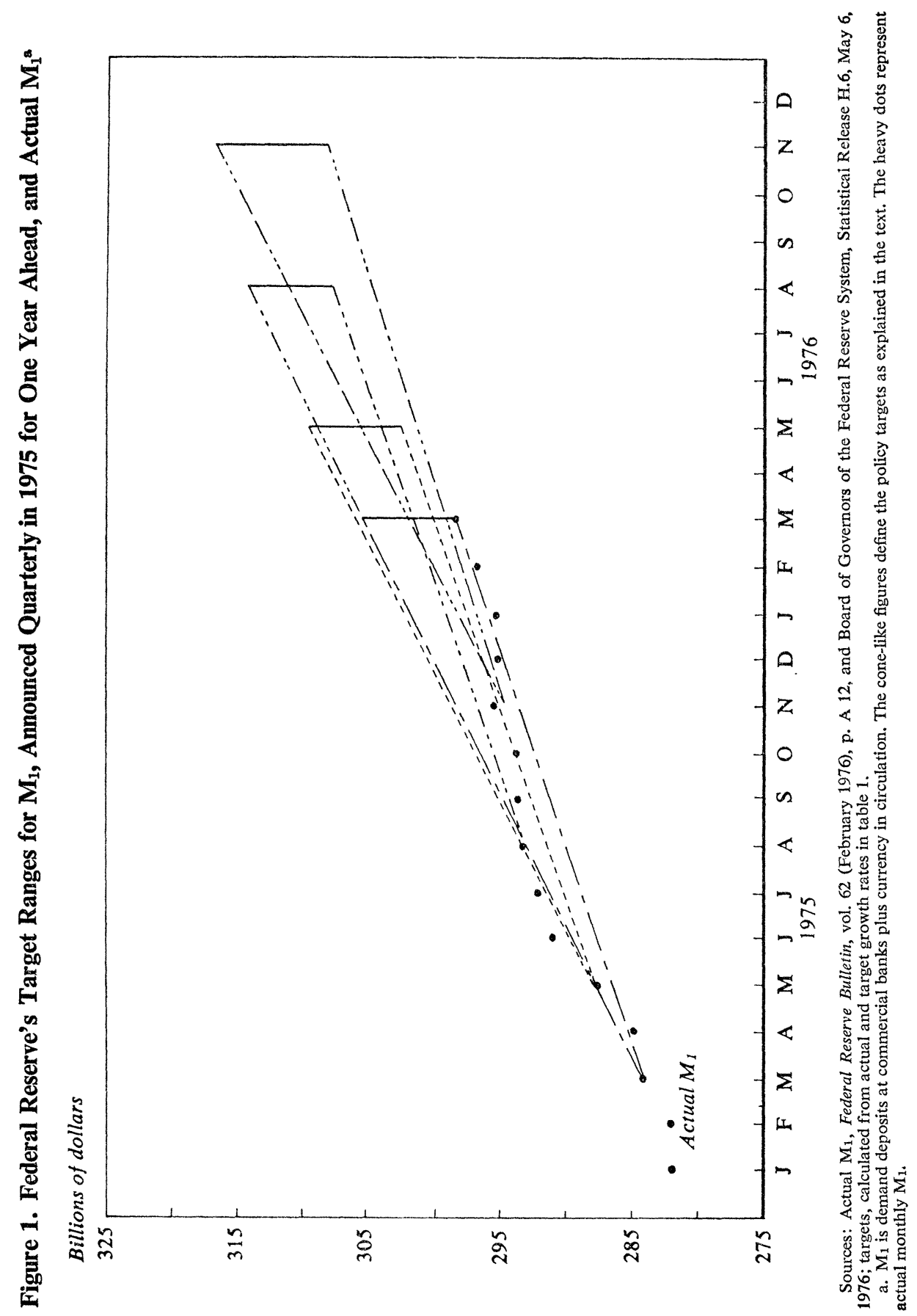


targets that either are inconsistent or represent inadvertent departures from (more or less) steady growth paths desired by policymakers. This problem is illustrated by the apparently haphazard relationship of the successive cones in figure 1 . The minor defect is the potential for inconsistency among targets for multiple variables.

\section{INCONSISTENCIES IN BASE LEVELS}

Defining monetary targets as the Fed has been doing is, I believe, unfortunate. Short-run fluctuations in the money stock may be desirable, or unavoidable, or both, but ought not to be automatically built into targets for one year ahead.

The economic arguments supporting this position can be explained readily. It is generally agreed that monetary fluctuations have effects on employment, prices, and so on that are distributed over time. If, for example, 6 percent growth in money is desirable, most economists will agree that 8 percent growth for one quarter followed by 4 percent growth the next will affect GNP and the other variables very much as would two quarters of steady 6 percent growth. If, however, an 8 percent quarter is followed by a string of 6 percent quarters, then, as the distributed-lag effects are worked out, the "extra" money growth of the 8 percent quarter will have an influence on the economy. Many economists would expect this unreversed extra growth to lower unemployment temporarily and eventually to raise the price level permanently above what it otherwise would have been. ${ }^{4}$

Moreover, the economy's response to monetary fluctuations may depend in part on the views held in the private sector about the Fed's monetary strategy. If the public believes that short-run monetary fluctuations will be reversed, the impact of those fluctuations on the economy is likely to be small; if these fluctuations are not reversed, especially if they continue

4. Put more precisely, a reduced-form equation explaining unemployment by money growth would have a fairly long distributed lag with negative early lag coefficients, positive later ones, and either a zero sum of the coefficients (vertical long-run Phillips curve) or, possibly, a somewhat positive sum. Similarly, the reduced-form explanation of the inflation rate by the growth rate of the money stock has a distributed lag whose coefficients sum to one. Other things equal, a quarter with 2 percentage points of extra money growth that is not reversed in subsequent quarters will affect unemployment and prices over time as indicated in the example in the text. If the extra money growth is reversed, the effects on unemployment and prices will be limited to the differences between the distributed-lag coefficients for adjacent quarters; these differences will be small if the distributed-lag patterns are, as usually assumed, reasonably smooth. 
quarter after quarter in the same direction, the speed of the response of the private economy eventually will change as households and firms come to expect these continuations rather than reversals.

Monetary fluctuations arising from transitory financial-market disturbances and data and control errors are caused by factors that are by definition "temporary"-short-lived relative to the length of the distributed-lag effects of money on the economy. A "permanent" change in conditionsa change enduring relatively long compared with distributed-lag effectsmay well call for a change in monetary targets. However, the present targeting procedure, by defining targets one year ahead in terms of growth rates on bases equal to actual levels of the money stock, implicitly treats all short-run monetary fluctuations as responses to permanent changes.

The quantitative importance of this issue for interpreting the Fed's monetary targets is most easily examined in the context of data revisions. These are readily observable and measurable, whereas control errors and the Fed's deliberate responses to temporary factors are not because the Fed's intentions are not. As an example, the first statement of one-year targets on May 1, 1975, included, among other data, the March 1975 level of $\mathbf{M}_{1}$, reported to be $\$ 286.8$ billion. As of this writing, however, $\mathbf{M}_{1}$ for March 1975-after a series of downward revisions reported in the issues of the Federal Reserve Bulletin for June and October 1975 and February 1976is reported to be $\$ 284.1$ billion, or 1.0 percent below the original estimate; a revision of this size is not trivial relative to a target growth range for $\mathbf{M}_{1}$ that is 2.5 percentage points wide.

Revisions of this magnitude are by no means uncommon, and while the Fed has always emphasized data problems in the abstract, it has offered no guidance-in the quarterly hearings or elsewhere-on how such revisions should affect the interpretation of the targets. Because of all the technical detail involved, the Fed will find it particularly awkward to explain a situation in which data revisions alter estimates for adjacent base quarters in opposite directions, producing target levels for adjacent quarters that are highly inconsistent (in the sense relevant to economic policy).

\section{MULTIPLE TARGETS}

The current practice of targeting three different variables raises relatively minor issues since the variables- $\mathrm{M}_{1}, \mathrm{M}_{2}$, and $\mathrm{M}_{3}$-are highly correlated. However, any question about the accuracy of the Fed's aim can be an- 
swered unambiguously only when the target ranges for all three are hit or they are all missed. Moreover, should all three target ranges be missed, but some on the high side and others on the low, it might be argued that the Fed did not "really" miss its announced targets. Indeed, if the differential growth rates among the targeted variables are not what the Fed expected, it probably makes good sense for the policymakers to aim above some and below others.

The major problem with multiple targets, in my opinion, is that the greater the number, the greater the possibility that the targeting procedure will lose meaning. With only one target variable, the Fed would be under greater pressure either to hit that target or to provide persuasive reasons for missing. The convenience of the opportunity to hit by chance one of many targets invites indecision and delay in either hitting the primary target or marshaling evidence to justify the miss. Finally, with many targets, the Federal Reserve finds it much easier to discuss its policy publicly in terms of a mass of technical detail and to rationalize the addition or elimination of variables from the targeted set. The credit proxy, for example, was dropped as a target variable with no mention whatsoever in the November 4, 1975, announcement of targets. ${ }^{5}$

\section{SIGNIFICANCE OF THESE PROBLEMS}

The issues examined above are important for two reasons. House Concurrent Resolution 133 presumably was designed to increase congressional influence over monetary policy, in part by providing regular quarterly hearings for congressional comment on Federal Reserve plans. If that was the congressional intent, the present ambiguities in the definitions of the targets, which invite confusion and misunderstanding, surely do not further it. Second, the Federal Reserve has devised a targeting system under which targets for several variables will from time to time be inconsistent and, worse yet, targets for the same variable in successive quarters will from time to time be inconsistent if the successive targets are meant

5. An explanation of the reasons for dropping the credit proxy should have been provided. Immediately following the quotation at the beginning of this report, H. Con. Res. 133 says that "nothing in this resolution shall be interpreted to require that such ranges of growth or diminution be achieved if the Board of Governors and the Federal Open Market Committee determine that they cannot or should not be achieved because of changing conditions. The Board of Governors shall report to the Congress the reasons for any such determination during the next hearings held pursuant to this resolution." 
to hold simultaneously. That monetary targeting need not entail these problems is shown below, in my discussion of an alternative procedure.

\section{Operational Significance of the Announced Targets}

In the four statements to date announcing targets, the Federal Reserve has adopted almost identical target growth rates, apparently reflecting the beliefs that unchanged money growth rates reflect unchanged policy and that no policy change has been needed. For example, the July statement contained this passage:

Economic prospects now are not materially different than the Federal Reserve anticipated 2 or 3 months ago, and we therefore as yet see no reason to alter the general course of monetary policy. Accordingly, the Federal Open Market Committee has reaffirmed its intent to seek the growth ranges announced earlier. ${ }^{6}$

But the Fed has also emphasized that short-run monetary control is very imprecise and that the one-year target growth rates do not necessarily imply comparable targets over shorter intervals. By reporting unchanged targets for growth rates-rather than levels-of the money stock, the Fed's announcements incorporate no provision for reversing abnormally high or low money growth over short periods and therefore are not in fact consistent with hitting the longer-run targets.

Since the Fed has emphasized that the targets for money growth are not to be interpreted as implying comparable targets over short periods, and since the procedure incorporates short-run monetary fluctuations into the target levels, the question is whether the Fed's open market operations will be designed to reverse short-run surges or shortfalls of money growth, or whether the new targets announced every quarter will in fact supersede previously announced targets. There is yet too little experience to suggest which course the Fed will choose. But in the particular case of the announcement on February 3, 1976, the market apparently accepted the latter interpretation of Fed response to the relatively slow $\mathrm{M}_{1}$ growth in the second half of 1975-2.7 percent annual rate, June to December. Before February 3, the money markets had been expecting the Fed to push interest

6. "Statement by Arthur F. Burns, Chairman, Board of Governors of the Federal Reserve System, before the Committee on Banking, Housing, and Urban Affairs, U.S. House of Representatives, July 24, 1975," in Federal Reserve Bulletin, vol. 61 (August 1975), p. 495. 
rates down; when the Fed reduced the minimum target growth rate for $\mathrm{M}_{1}$ from 5 to 4.5 percent, money-market rates rose.

My prediction is that, for the most part, the Fed will tend to adjust the money stock to stay within the original target range. With three aggregates targeted, the target for one rather than its level might be adjusted-a quite sensible action since available evidence gives no strong reason for favoring one over another. But I find it difficult to believe that the Fed would risk a situation in which all of its target variables might fall significantly below (above) their originally projected and publicly announced target ranges at a time when the economy might in retrospect prove to have been weak (strong).

\section{An Alternative Method of Expressing Targets for Monetary Aggregates}

The problems with the current procedures could be largely avoided by expressing the targets for $M_{1}, M_{2}$, and $M_{3}$ as illustrated for $M_{1}$ in figure 2 . In this figure, the most recently available official data on $M_{1}$ are plotted as a series of points.

The solid trend line starts at the actual 1975:1 average for $M_{1}$, with a growth rate of $6 \frac{1}{4}$ percent, the midpoint of the original $5-7 \frac{1}{2}$ percent targets. ${ }^{7}$ The 5-71/2 percent targets were announced three times, and so the $6 \frac{1}{4}$ percent trend line is simply extended out to $1976: 3$, still using the original 1975:1 base, rather than the actual money stock in the "new" base quarter.

The $M_{1}$ targets announced February 3, 1976, were $4 \frac{1}{2}-71 / 2$ percent growth, with a midpoint of 6 percent. A vertical bar is drawn in the middle of $1976: 3$, the last quarter to which the $61 / 4$ percent midpoint target applies. The new 6 percent midpoint target rate produces a path starting from a base level defined by the old target path for the money stock rather than by the actual 1975:4 average money stock. The 6 percent path, of course, gradually diverges from the old $6 \frac{1}{4}$ percent path. Each time the 6 percent target is renewed, the 6 percent trend line will be extended and the vertical bar drawn three months further into the future.

7. The careful eye may note that this trend line has a slight upward curvature since it was constructed by applying the money growth rate with quarterly compounding that is equal to $6 \frac{1}{4}$ percent with annual compounding. 


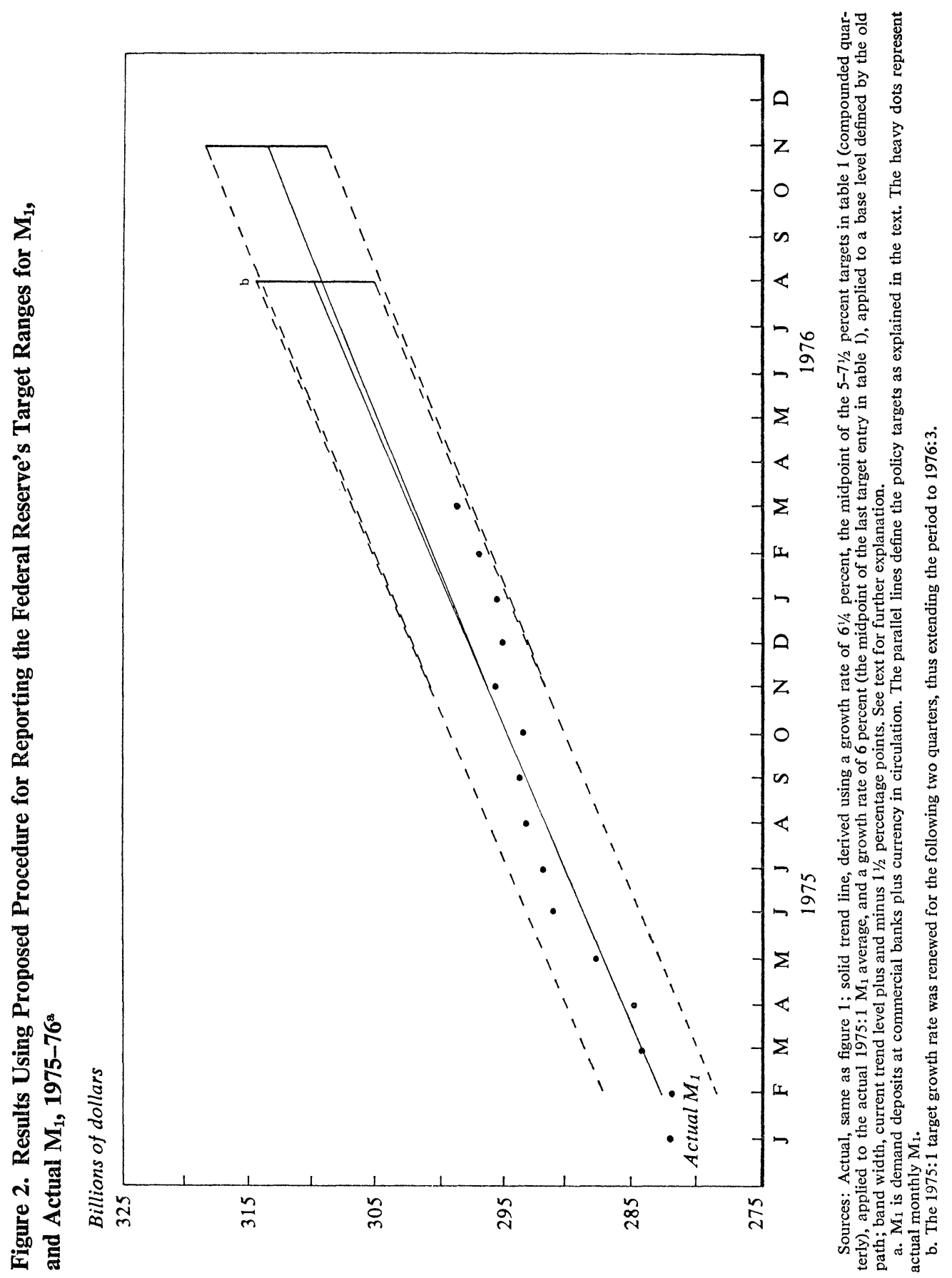


The band defined by the dashed lines in the figure is a suggested reinterpretation of the target range. The present $4 \frac{1}{2}-71 \frac{1}{2}$ percent range may be viewed as a level four quarters away equal to 1.06 times the current level, plus or minus 0.015 of that level. In figure 2, the dashed bands are drawn $1 \frac{1}{2}$ percentage points above and below the target path represented by the solid line. The width of the band in November 1976 represents the same dollar spread (except for a very minor difference due to different base levels) as the width of the cone for November 1976 in figure 1 . The band width has been selected in this way in order that the suggested procedure correspond as closely as possible to the current procedure in the amount of leeway the Federal Reserve believes appropriate in selecting one-year targets for money growth.

Under the suggested procedure the Federal Reserve would present its targets for the growth of monetary aggregates not in terms of a range but in terms of one number defining the central growth trend and a second number defining band limits as percentages of the level of the aggregate around the central growth trend. ${ }^{8}$ By presenting charts such as figure 2, the Fed would direct the public's attention to the level of the money stock within the band instead of actual rates for money growth over short periods of time. For example, as of this writing, the March 1976 level of $M_{1}$ would be viewed as being somewhat above the lower band rather than as having risen in the last six months at the relatively low rate of only 3.3 percent per year. This approach would also make it easy to provide a feel for data errors. Each observation of the money stock could be presented as a short bar representing the point estimate plus and minus the estimated standard error.

\section{General Comments on Interest-Rate Targeting}

Although economists differ on the desirability of announced-and unannounced-monetary targets, they generally agree that it is technically feasible to hold a particular definition of the money stock within a band

8. The language of House Concurrent Resolution 133 seems to require disclosure of target growth rates based on actual base-period data for the money stock. These targets should be obtained by calculation from the actual base level to the ends of the target range one year ahead defined by the band in figure 2 . When base-period data are revised, the previously announced target growth rates would be revised by redoing the above calculation rather than automatically revising the target levels for one year ahead. 
as defined in figure 2. Disturbances may make it undesirable to hold a money-stock variable within such a band, but are unlikely to make it impossible to do so. Of course, it may not be possible to keep several different monetary variables within predetermined bands.

Interest-rate targeting is another matter. If interest-rate targets were announced-with or without accompanying monetary targets-missing them would be the rule rather than the exception unless the target bands were very wide. An attempt to hold a particular interest rate in a relatively narrow band when market pressures tend to push it outside is cumulatively destabilizing. Interest-rate pegging was abandoned after World War II not simply because it was undesirable but because it was infeasible. The market forces that destroyed the interest-peg policy did act slowly-surprisingly so, in my opinion-but they now operate much more rapidly. Under present conditions, an announced one-year target for interest rates would have to be abandoned every quarter, and in fact ordinarily would not last even through a quarter.

Short-run interest-rate targets for short-term securities could be announced and achieved most of the time, but would cause constant trouble. If publicly committed to an interest-rate range, the Federal Reserve would be blamed, much more than at present, for increases in interest rates, since they would reflect either failure to hold to announced targets or deliberate and announced changes in targets. Though confined to shortterm securities, targets would nevertheless affect the long-term market, where capital losses from rate increases can be substantial.

If Fed policy is linked directly and immediately to the capital gains and losses experienced by bondholders, great pressure will be mobilized for political decisionmaking in these tax- and subsidy-like policy actions-a process involving public debate and the more or less formal approval of policy changes by elected public officials.

During this political decisionmaking process, market reactions anticipating interest-rate changes would make it more difficult to achieve targets, and political reactions after policy changes would make it more difficult to change future targets. On the other hand, it is feasible to determine money-stock targets through the political process. Changes in the money stock do not have unambiguous effects on the direction of interest-rate changes, and delay in changing the rate of money growth is not cumulatively destabilizing.

In summary, a precondition for announced policy targets-in the sense 
of targets for variables under the control of the policymakers rather than in the sense of goals for variables like employment or inflation-is that the targets be achievable. If announced monetary-policy targets are viewed as desirable for some combination of reasons involving the accountability of public officials and the provision of information to improve the functioning of private markets, those targets must involve monetary magnitudes rather than interest rates. If a formal procedure of announced targets for interest rates is introduced, the effects of the procedure are certain to be harmful and the system is likely to be short-lived. 